death. There are, however, certain considerations which may serve to throw light upon the abrupt termination of his malady. Aside from sunstroke, lightning and other forms of traumatism, the causes of instantaneous dissolution may be put down as hæmorrhage into the medulla and paralysis of the heart or, in other words, arrest of the heart in diastole. Bulbar hæmorrhage, sufficient to promptly destroy life, must be so copious as to involve the respiratory or cardiac centres, or both; and such a hæmorrhage is extremely rare in the young, and even in the aged is not common. Disease of the blood-vessels of the part is for the most part essential to its occurrence, and degenerative weakness of the arterial coats is rare in individuals under $4 \circ$, except from syphilis or prolonged vascular strain in cases of aortic regurgitation. Yet, death from bulbar, hæmorrhage is so exceptional, even in cases which present the requisite cardiac and vascular conditions, that, even granting the existence of aortic insufficiency in the case of Dr. C., the probabilities would be against his death from extravasation of blood into the medulla.

When bulbar embolism is the cause of such hæmorrhage, death is usually preceded by well marked symptoms referrable to a profound centric lesion, and Dr. C. is reported to have fallen to the floor and died without the utterance of a sound. Consequently, our inquiry is limited to that other and not infrequent cause of sudden death, abrupt failure of the heart. Here we are at once confronted by two considerations, first, that Dr. C. was supposed to have mitral regurgitation, secondly, that his disease was not thought to present symptoms of special gravity. As to the former, as is well known, the usual cause of death in mitral disease is gradual failure of the right side of the heart, and not sudden diastolic paralysis of the left ventricle. This latter occurs when compensatory hypertrophy has yielded to dilatation, commonly in cases of fatty degeneration or over distension of the ventricular walls from the force of the regurgitant blood in aortic incompetence. There was no autopsy in the case of Dr. C. and hence our $k$ nowledge as to the exact nature of his heart-disease, rests on the report of a mitral systolic murmur. If one were inclined to be captious, he might doubt the correctness of this diagnosis, if-as is commonly the case-ausculation had been made with the unaided ear and through a portion of the clothing. Under such circumstances, a loud systolic murmur heard throughout the præcordia and preceded by a faint first sound, might be mistaken for a mitral systolic murmur, and the first sound for the second sound. Had this been the actual state of affairs, his sudden death after the exertion of pulling a tooth might be readily understood.

Granting, however, that his disease was in reality mitral regurgitation, his sudden death is not wholly in explicable; but it must presuppose greater cardiac feebleness and ventricular dilatation than appear to have been recognized. Four weeks prior to his death he complained of symptoms referrable to hepatic engorgement, which, although they yielded to treatment, were followed by debility. It is not uncommon for patients with heart-disease to refer their symptoms to some other organ than the one mainly affected. Furthermore, the Doctor was an energetic man, very likely to perform his daily duties without complaint. Hence it is reasonable to assume that his condition was far graver than he himself would admit or others recognize. It is probable, therefore, that compensation had been ruptured and grave dilatation established. In this condition of the heart the physical exertion of pulling a tooth could, by occasioning sudden increase of the arterial tension through muscular contraction and expiratory increase of the intra-bronchial atmospheric pressure, cause a degree of ventricular over-distension from which the weakened heart could not recover.

Although such a sudden death is rare in mitral disease, it is not unknown. I have myself lost a pa. tient, the subject of mitral disease, in this way. She sat up in bed to drink a cup of tea and suddenly fell back upon her pillow dead.

70 Monroe St., Room 29, Chicago.

Robert H. Babcock, M.D.

\section{OPIUM INEBRIETY AND INFANTILE} MORTALITY.

Dear Str:-I am desirous of obtaining facts regarding the relation of opium inebriety in mothers to infantile mortality.

Dr. Frank B. Earle, of Chicago, informed me that he "recently attended a woman taking about twelve grains of morphia daily, who has lost four successive babies between the second and fourth day, all having died in collapse." If any reader of your journal will furnish me details of a similar case, I will much appreciate his courtesy and give him full credit. $3^{1} 4$ State St., Brooklyn, N. Y. J. B. Mattison, M.D.

\section{BOOK REVIEWS.}

A Practical Treatise on Diseases of the Eye. By Dr. Edouard Meyer, Professor à l'école Pratique de la Faculté de Médecine de Paris, Chevalier of the Legion of Honor, etc. Translated, with the assistance of the author, from the Third French Edition, with additions as contained in the Fourth German Edition, by FreEland FerGUS, M.B., Ophthalmic Surgeon Glasgow Royal Infirmary, Assistant Surgeon Glasgow Eye Infirmary. With 267 illustrations and 3 colored plates. 8vo, pp. $6+7$. Philadelphia: P. Blakiston, Son \& Co. I 887 .

Dr. Meyer's book is so generally recommended and employed in Germany and France that it is considered the student's text.book "par excellence." It has gone through several French and German editions, has been translated into Spanish, Polish, Russian, Italian and Japanese languages. We are indebted to Dr. Fergus for an English translation, which lies before us. Its general arrangement does not differ materially from that usually adhered to by text-book writers. Every subject is discussed in 